\title{
Notes on the vocalizations of Chestnut-fronted Shrike-babbler (Pteruthius aenobarbus)
}

Peter Boesman

In the following we briefly analyze and compare voice of the different races of Chestnutfronted Shrike-babbler (Pteruthius aenobarbus). We also try to quantify the extent of any vocal differences using the criteria proposed by Tobias et al. (2010), as a support for taxonomic review. We have made use of sound recordings available on-line from Xeno Canto $(X C)$.

Voice has already been analyzed in Rheindt \& Eaton (2009), concluding that there are 2 distinct song types, a 'trilling song' exclusively delivered by the Javan race (nominate) and a clicking song delivered by the mainland race intermedius (and rarely by the Javan race).

While this case looks rather straightforward at first sight, a closer looks reveals a more nuanced picture.

Some examples of song from Java (ordered from fast to slow):

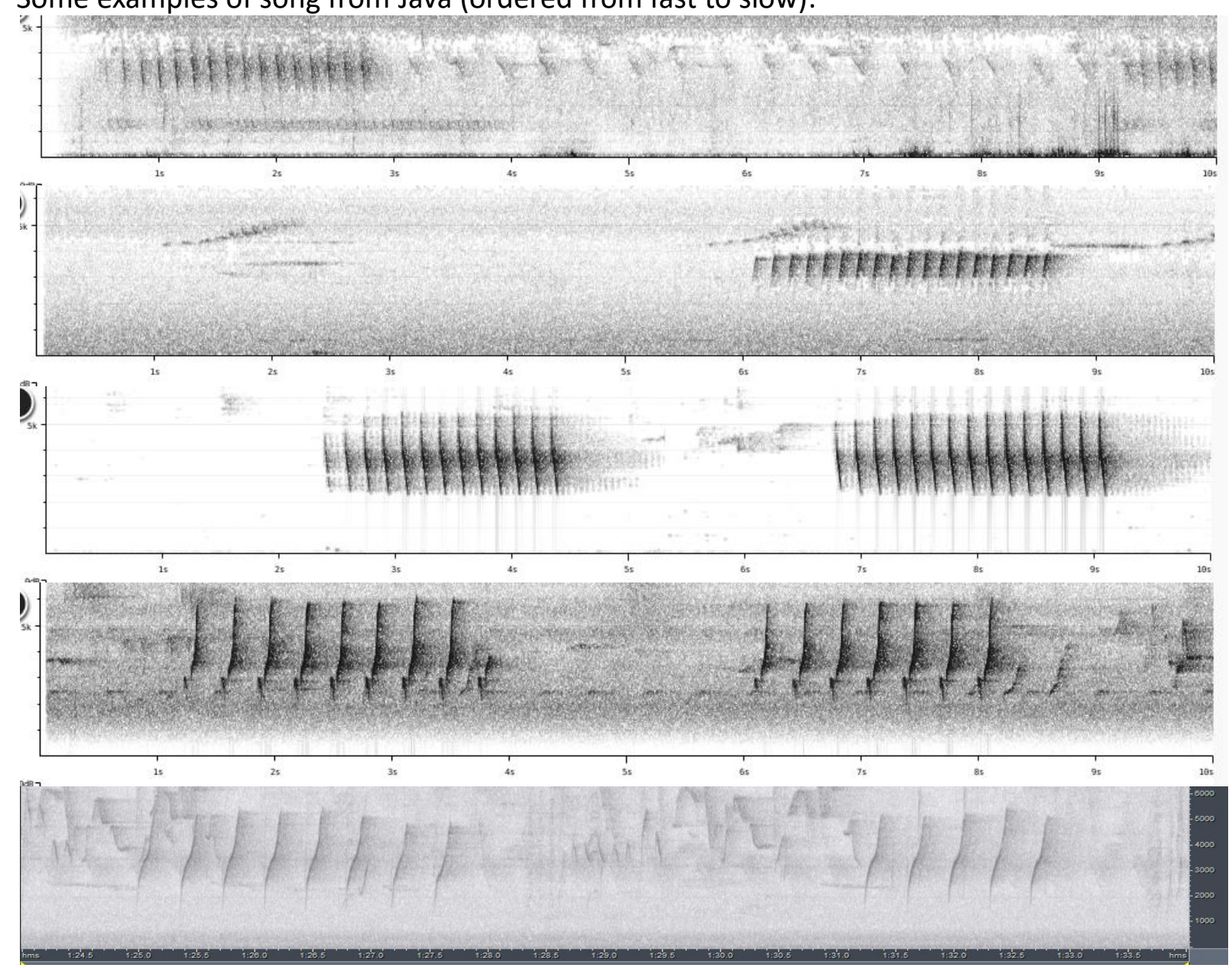




\section{HANDBOOK OF THE \\ BIRDSPF,THE WORLD \\ Alve}

\section{ORNITHOLOGICAL NOTES}

or doubled:

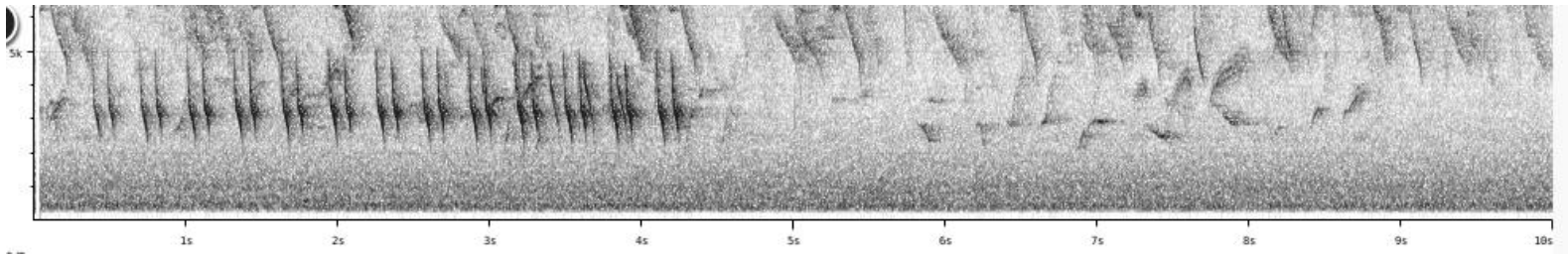

Surprisingly on the mainland, only recordings are available from Vietnam, despite the large mainland distribution:

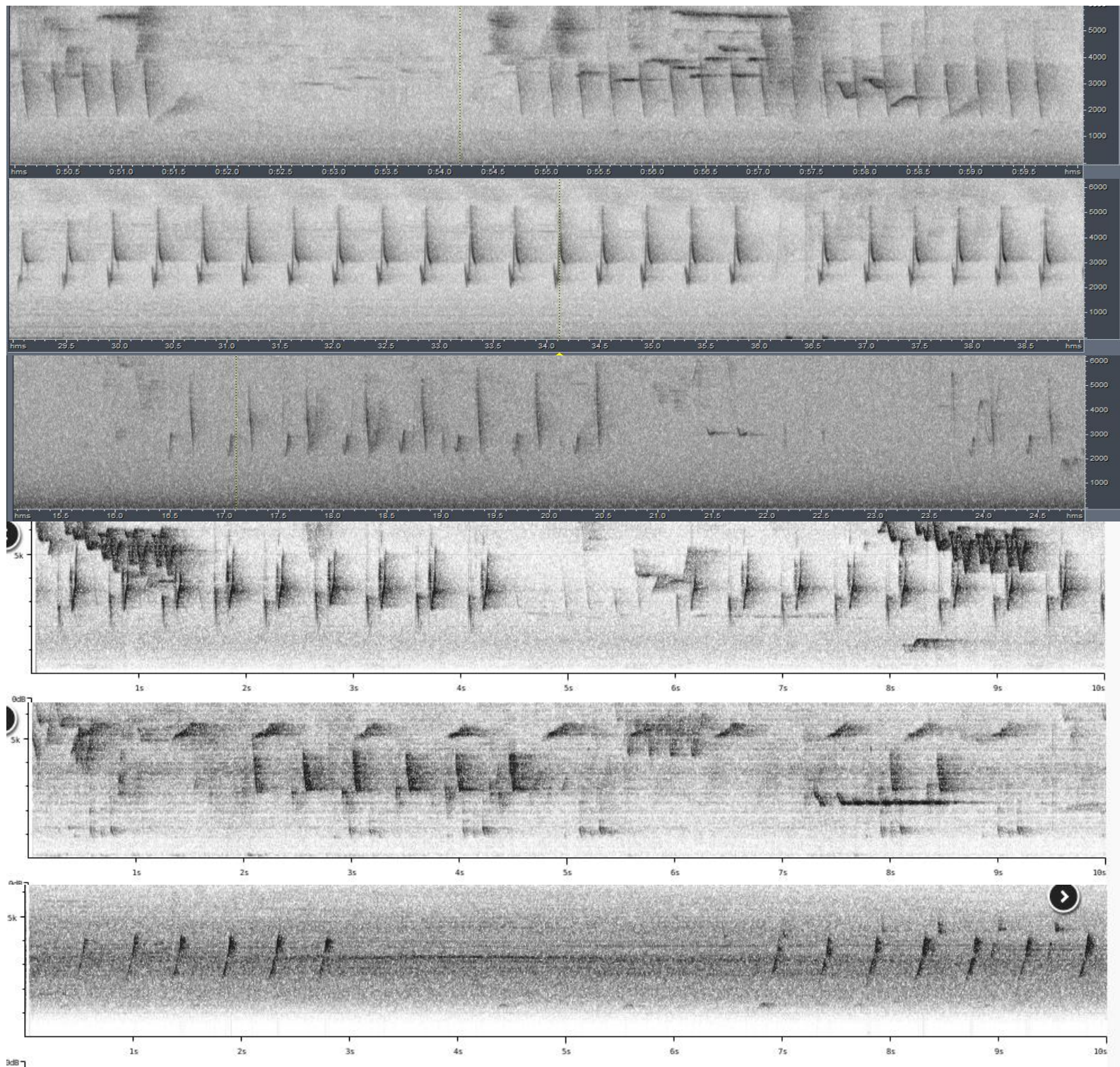

At least in Vietnam, the mainland races thus seems to lack the very fast delivered song. (This is race intermedius, with no further information about the three (?) other mainland races).

Both groups give a song consisting of either a single or a double note repeated. Note shapes are quite similar between the 2 groups. 


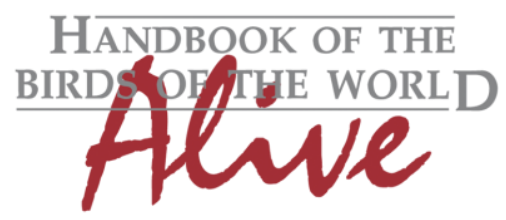

\section{ORNITHOLOGICAL NOTES}

Whether the faster song is truly a 'different song' as suggested in aforementioned study is not directly clear from above examples. They compare with P. melanotis, indicating that this species has also a trilling song, and that this may be a reason why mainland $P$. aenobarbus has ceased to use this vocalization.

Some examples of P. melanotis:

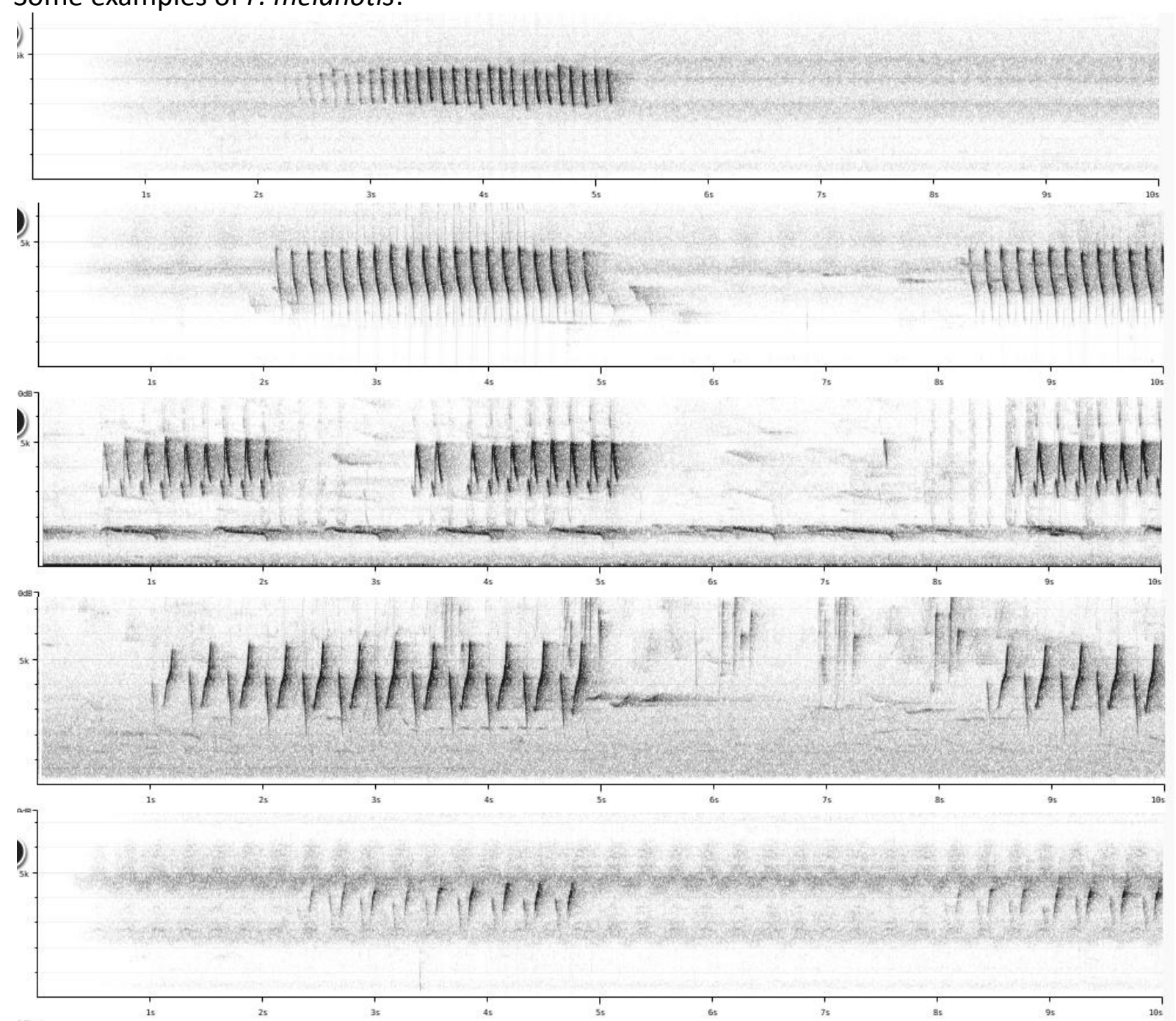

(example 1, 2 and 5 all taken at a single locality)

Looking at the above examples, one can't really divide into 2 distinct song types based on pace, the song of $P$. melanotis is rather a continuum when looking at pace, ranging from rapid trilling song to slower 'clicking' song.

If we apply the same reasoning to $P$. aenobarbus we thus should rather treat the song as a single song type with variable pace (or else a 'single note repeated' and a 'double note repeated' song). 

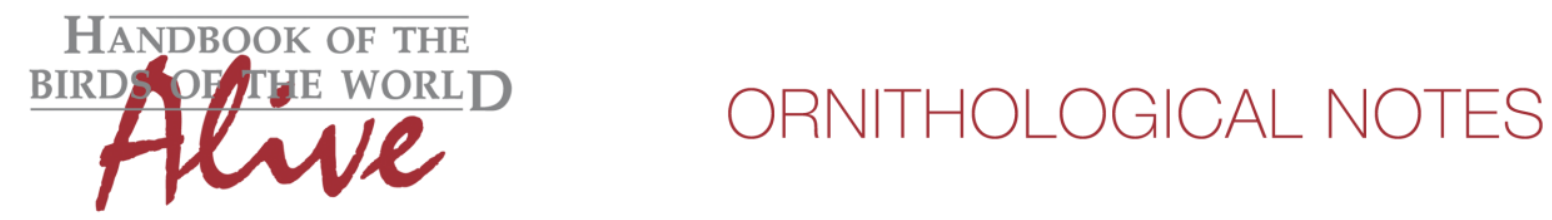

Based on the available recordings, we could thus quantify by measuring pace. From the above examples it is clear that pace range of Java and Vietnam recordings are quite different but have a slight overlap, which is typically given a score 2 . (We need to define pace here as the period length, thus either the length between 2 notes in the case of a single note repeat, or the length between 2 identical notes in the case of a double note repeat...)

Besides pace, other basic sound parameters to look at are max. and min. frequency, frequency range, note length, \# of notes etc. Again from the above examples, there is however very little difference to be found. Even note shapes are overall hardly different. One distinguishing feature is that the relative frequency with which a repeated single note is given and a repeated phrase of 2 different notes is given differs: in Java birds mainly sing repeated single notes, in Vietnam birds mainly sing repeated double notes (mainly 'trilling' vs. mainly 'clicking'). This could be given a score 1 (obviously the latter is stretching the application of Tobias criteria, and is somewhat speculative given the few recordings we have of the mainland group outside Vietnam).

This would lead to a total vocal score of 3 , with considerable reservation however due to the number of assumptions (no fast songs on the mainland, other races sing as race intermedius in Vietnam, birds of E Java sing as birds of W Java etc.).

This note was finalized on 6th February 2016, using sound recordings available on-line at that moment. We would like to thank in particular the sound recordists who placed their recordings for this species on XC: Peter Boesman, Brian Cox, James Eaton, Frank Lambert, Hans Matheve, Mike Nelson, Craig Robson and Ding Li Yong.

\section{References}

Rheindt, F.E. and Eaton, J.A. (2009). Species limits in Pteruthius (Aves: Corvida) shrikebabblers: a comparison between the Biological and Phylogenetic Species Concepts. Zootaxa 2301: 29-54.

Tobias, J.A., Seddon, N., Spottiswoode, C.N., Pilgrim, J.D., Fishpool, L.D.C. \& Collar, N.J. (2010). Quantitative criteria for species delimitation. Ibis 152(4): 724-746.

\section{Recommended citation}

Boesman, P. (2016). Notes on the vocalizations of Chestnut-fronted Shrike-babbler (Pteruthius aenobarbus). HBW Alive Ornithological Note 166. In: Handbook of the Birds of the World Alive. Lynx Edicions, Barcelona. (retrieved from http://www.hbw.com/node/932096 on 19 August 2016). 